\title{
Article \\ Quantification of the Lifecycle Greenhouse Gas Emissions from Nuclear Power Generation Systems
}

\author{
Akhil Kadiyala ${ }^{1}$, Raghava Kommalapati ${ }^{1,2, *}$ and Ziaul Huque ${ }^{1,3}$ \\ 1 Center for Energy \& Environmental Sustainability, Prairie View A \& M University, Prairie View, \\ TX 77446, USA; akkadiyala@pvamu.edu (A.K.); zihuque@pvamu.edu (Z.H.) \\ 2 Department of Civil \& Environmental Engineering, Prairie View A \& M University, Prairie View, \\ TX 77446, USA \\ 3 Department of Mechanical Engineering, Prairie View A \& M University, Prairie View, TX 77446, USA \\ * Correspondence: rrkommalapati@pvamu.edu; Tel.: +1-936-261-1660
}

Academic Editor: Pierre Trambouze

Received: 5 July 2016; Accepted: 19 October 2016; Published: 25 October 2016

\begin{abstract}
This paper statistically quantifies the lifecycle greenhouse gas (GHG) emissions from six distinct reactor-based (boiling water reactor (BWR), pressurized water reactor (PWR), light water reactor (LWR), heavy-water-moderated reactor (HWR), gas-cooled reactor (GCR), fast breeder reactor (FBR)) nuclear power generation systems by following a two-step approach that included (a) performing a review of the lifecycle assessment (LCA) studies on the reactor-based nuclear power generation systems; and (b) statistically evaluating the lifecycle GHG emissions (expressed in grams of carbon dioxide equivalent per kilowatt hour, $\mathrm{gCO}_{2} \mathrm{e} / \mathrm{kWh}$ ) for each of the reactor-based nuclear power generation systems to assess the role of different types of nuclear reactors in the reduction of the lifecycle GHG emissions. Additionally, this study quantified the impacts of fuel enrichment methods (centrifuge, gaseous diffusion) on GHG emissions. The mean lifecycle GHG emissions resulting from the use of BWR (sample size, $\mathrm{N}=15)$, PWR $(\mathrm{N}=21)$, LWR $(\mathrm{N}=7), \operatorname{HWR}(\mathrm{N}=3), \mathrm{GCR}(\mathrm{N}=1)$, and FBR $(\mathrm{N}=2)$ in nuclear power generation systems are $14.52 \mathrm{gCO}_{2} \mathrm{e} / \mathrm{kWh}, 11.87 \mathrm{gCO}_{2} \mathrm{e} / \mathrm{kWh}$, $20.5 \mathrm{gCO}_{2} \mathrm{e} / \mathrm{kWh}, 28.2 \mathrm{gCO}_{2} \mathrm{e} / \mathrm{kWh}, 8.35 \mathrm{gCO}_{2} \mathrm{e} / \mathrm{kWh}$, and $6.26 \mathrm{gCO}_{2} \mathrm{e} / \mathrm{kWh}$, respectively. The FBR nuclear power generation systems produced the minimum lifecycle GHGs. The centrifuge enrichment method produced lower GHG emissions than the gaseous diffusion enrichment method.
\end{abstract}

Keywords: lifecycle assessment; greenhouse gas emissions; nuclear energy; power generation; reactors; enrichment

\section{Introduction}

Nuclear energy may be defined as the energy harnessed from controlled reactions within the nuclei of atoms that release energy. Typically, the controlled reactions are performed inside a nuclear reactor that comprises of seven major components-fuel, moderator, control rods, coolant, pressure vessel or pressure tubes, steam generator, and containment [1]. Uranium (in the form of uranium oxide fuel rods) is the most widely used fuel in nuclear reactors. The moderator is used to slow down the neutrons that are released from fission to enable more fission. Water (ordinary water) is the most widely used moderator. Alternatively, heavy water $(10 \%$ denser than ordinary water with a neutron moderating ratio 80 times higher than ordinary water) and graphite may also be used as moderators. The control rods are neutron-absorbing materials that are inserted or withdrawn from the core to control the rate of reaction, or to halt it. The control rods are made from one of the materials such as cadmium, hafnium, and boron. The coolant is a fluid that circulates through the core to transfer heat. Water is the most widely used coolant. A pressure vessel is a robust steel vessel that contains nuclear fuel, moderator, control rods, and coolant. Pressure tubes are a series of tubes containing the 
fuel through which the coolant is circulated and surrounded by a moderator. The steam generator is a heat exchanger that transmits the thermal energy generated in the reactor core to produce steam for the turbine from a working fluid. The containment is a thick concrete and steel structure, which is designed to protect the reactor from outside intrusion and to protect the people outside from the effects of radiation in case of any serious malfunction within the nuclear reactor.

The total electricity generated in 2012 across the world was reported to be 21.53 trillion kilowatt hours (kWh) [2]. Nuclear energy accounted for 2.35 trillion kWh (10.9\%) of the world's total electricity generated in 2012. The projected world electricity generation for 2040 is 39 trillion $\mathrm{kWh}$ (an increase by $81 \%$ from 2012) [3]. Nuclear energy has been projected to account for 5.5 trillion $\mathrm{kWh}(14 \%)$ of the world's total electricity generation in 2040, with an annual increase of $2.5 \%$. These statistics indicate that nuclear energy has a vital role to play in meeting the world's energy demand.

Under such circumstances, one needs to statistically quantify the lifecycle greenhouse gas (GHG) emissions resulting from the adoption of different types of nuclear power generation systems. The lifecycle assessment (LCA) approach helps quantify the net GHG emissions resulting from the use of nuclear energy as a fuel. LCA is an analytical method that provides an assessment of the environmental impacts of the considered products and technologies from a 'cradle to grave' systems perspective utilizing the detailed input and output parameters that operate within the designated system boundaries.

Many studies analyzed the LCA of nuclear power generation systems [4-29]. The use of nuclear power generation systems across the world is being encouraged in view of the advantages that nuclear energy serves as an alternative to the rapidly depleting fossil fuels, accounts for the intermittency and the unpredictability issues associated with the renewable energy sources by continually generating power (approximately $90 \%$ of the annual time), and helps improve air quality considering that they produce no GHGs or emissions that causes the formation of acid rain or urban smog [30]. The extensive use of nuclear power generation systems is inhibited by issues such as the management of nuclear waste, the recovery of investment costs, and security concerns.

The majority of the nuclear LCA publications to date emphasized the determination of the lifecycle GHG emissions from select nuclear power generation systems. There were limited studies [31,32] that analyzed the lifecycle GHG emissions across a broader spectrum of nuclear power generation systems. None of the earlier studies quantified the lifecycle GHG emissions and compared them across all the currently available distinct nuclear reactor-based and fuel enrichment method-based power generation systems. This study aims to fill this knowledge gap by performing a review of the literature on all the currently available nuclear LCA studies, followed by a statistical evaluation of the lifecycle GHG emissions from the reviewed nuclear power generation systems individually. The results from the statistical evaluation of the lifecycle GHG emissions will assist energy policy makers and environmental professionals in identifying and encouraging the use of environmentally friendly nuclear options to generate power with minimal GHG emissions. Performing the LCA for nuclear power generation systems would additionally provide details that may be incorporated into making a comparison with the GHGs emitted from other power generation technologies.

\section{Methodology}

A review of the literature showed that the nuclear power generation systems may be categorized on the basis of the type of nuclear reactor, which are characterized by the fuel type, the moderator type, and the coolant type. The six common types of nuclear reactors that are employed for power generation across the world are as follows [33]:

- Boiling water reactor (BWR): BWRs are a single-loop system that makes steam in the primary circuit itself above the reactor core. BWRs generally operate using uranium dioxide $\left(\mathrm{UO}_{2}\right)$ as the fuel and water $\left(\mathrm{H}_{2} \mathrm{O}\right)$ as the moderator as well as the coolant. The reactor core in a BWR comprises of up to 800 fuel assemblies or more. The fuel assemblies of the BWR are comprised of a $7 \times 7$ to $10 \times 10$ square array of fuel pins, surrounded by a metal fuel channel that prevent the movement 
of steam-water mixture between the fuel assemblies, thereby ensuring adequate cooling of the fuel assemblies. The feedwater (pumped into the steel reactor vessel containing the core) is converted to steam as a result of the heat generated by fission chain reactions occurring within the fuel pins. The reactivity control is implemented through a combination of neutron-controlling fuel rods (made of boron carbide-filled pins) and coolant flow adjustment. The steam-water mixture that leaves from the top of the core enters the stage of moisture separation where the water droplets are removed before the steam is allowed to enter the steam line. The steam line then directs the steam to turn the turbine generator to produce electricity.

- Pressurized water reactor (PWR): PWRs have water in a primary cooling/heat transfer circuit and generate steam in a secondary circuit. Like BWRs, PWRs also operate with $\mathrm{UO}_{2}$ as the fuel and $\mathrm{H}_{2} \mathrm{O}$ as the moderator as well as the coolant. The reactor core in a large PWR comprises of 150 to 200 fuel assemblies, or more. The fuel assemblies of the PWR are comprised of a $14 \times 14$ to $17 \times 17$ square array of fuel pins or up to 331 hexagonal fuel pins. In the PWRs, there is no metal fuel channel as the single-phase primary fluid (water) operated better than the BWR's boiling coolant. The water in the primary loop is maintained as a liquid under high pressure and enters the steel reactor vessel containing the core through inlet nozzles. The water flows downward along the inner vessel wall and flows up through the fuel assemblies gathering heat energy, and exits through the outlet nozzle as a liquid. The heat energy from the primary loop is extracted by the steam generators (secondary circuit) that convert the water into steam. The reactivity control is implemented through neutron-controlling fuel rods (made of boron carbide-filled pins) and soluble neutron poison boric acid. The steam-water mixture that leaves from the top of the secondary circuit enters the stages of moisture separation. The steam line then directs the steam to turn the turbine generator to produce electricity.

- Heavy-water-moderated reactor (HWR): HWRs are also a two-loop system like PWRs with the exception that heavy water (in primary loop) transfers the heat to water (in secondary loop) for generation of steam. The HWRs operate with $\mathrm{UO}_{2}$ as the fuel and heavy water/deuterium oxide $\left(\mathrm{D}_{2} \mathrm{O}\right)$ as the moderator as well as the coolant. The Canadian Deuterium-Uranium (CANDU) reactor is the signature representative of HWRs. The pressurized heavy water (PHW) CANDU also contains a two-loop system, like the PWRs, with the primary PHW loop transferring the heat to a loop of ordinary water for steam production. The primary fluid, i.e., the PHW is distributed among the pressure tubes that pass through a large Calandria vessel that contains a separate heavy water moderator. The coolant is collected in two separate loops. The fuel assemblies of the HWRs are comprised of uranium dioxide fuel pellets clad in zirconium. The reactivity control is accomplished through online fueling (a machine-based technique that enables changing the fuel of a nuclear reactor, while the reactor is critical) that is required to compensate for low reactivity inherent in natural uranium. The steam-water mixture that leaves from the top of the secondary circuit enters the stage of moisture separation for segregation of steam, which is passed in to the steam line to finally turn the turbine generator for producing electricity.

- Gas-cooled reactors (GCR): The initial version of GCRs used natural uranium as the fuel, graphite as the moderator, and natural-circulation air for cooling. Subsequent GCRs utilized graphite as the moderator in combination with natural or enriched uranium as the fuel, and carbon dioxide $\left(\mathrm{CO}_{2}\right)$ or helium as the coolant. The Magnox reactor having a two loop system with $\mathrm{CO}_{2}$ as a primary coolant, gas to waste stream generators, and natural uranium as the fuel is representative of the GCRs. The development of $\mathrm{CO}_{2}$ gas-cooled reactors is inhibited by the coolant limitations such as excessive corrosion in piping and steam generators under high temperatures.

- Light-water-cooled graphite moderated reactor (LWGR)/pressure tube graphite reactor (PTGR): The LWGR/PTGR uses graphite as an array of blocks to act as a moderator in controlling the neutrons and comprises of a direct steam cycle like BWRs. Like the HWRs, the LWGR/PTGR reactors also have a complex pressure tube design with separate coolant and moderator in the core. LWGRs/PTGRs operate with $\mathrm{UO}_{2}$ as the fuel, graphite as the moderator, and $\mathrm{H}_{2} \mathrm{O}$ as the coolant. 
The soviet-era Reaktor Bolshoy Moshchnosti Kanalnyy (RBMK) is representative of the PTGR. There are approximately 1900 vertical pressure tubes that accommodate multiple fuel assemblies or control rods in a RBMK reactor. The pressure tubes in the RBMK reactor are surrounded by an array of long, square-shaped graphite blocks set side by side to resemble a cylinder shape that functions as a moderator. In the RBMK reactor, water is introduced from the bottom of the core and enters the pressure tubes. The water then boils due to the fission heat from the fuel pins. The steam is then drawn out for use in one of the two steam generators. The pressure tubes and the piping are enclosed within a steel reactor vessel. The fuel assemblies of the RBMK reactor include two sub-assemblies of 18 zirconium-clad fuel pins of enriched uranium. The reactivity control is accomplished through online fueling, as noted in the case of HWRs.

- Fast breeder reactor (FBR): FBRs work on the principle of breeding more new fuel than that is required for the neutron chain reaction. FBRs generally operate using $\mathrm{UO}_{2}$ or plutonium dioxide $\left(\mathrm{PuO}_{2}\right)$ as the fuel, have no moderator, and use sodium (Na) as the coolant. The liquid metal fast breeder reactor (LMFBR) represents the FBR and has three loops (first two loops with Na, third loop with water) in the steam cycle. The intermediate loop isolates the first loop from coming in contact with the third loop. The primary loop Na becomes radioactive from neutron absorption and also picks up fission-product radionuclides. When this comes in contact with water, it can lead to precipitation as an exothermic reaction and radioactive contamination. The fuel for LMFBR comprises of mixed-oxide $\left(\mathrm{MOX}: \mathrm{PuO}_{2}-\mathrm{UO}_{2}\right)$ pellets that are loaded into thin stainless steel cladding tubes to form hexagonal array fuel assemblies. Additional depleted or natural uranium is used as a cover to the MOX core to optimize the breeding. The reactivity control is accomplished through the use of neutron-poison control rods.

Amongst the currently available commercial nuclear reactors across the world, PWRs (number of installations, $\left.N_{i}=277\right)$ are the most widely used nuclear reactors, followed by BWR $\left(N_{i}=80\right)$, $\operatorname{HWR}\left(\mathrm{N}_{\mathrm{i}}=49\right), \operatorname{GCR}\left(\mathrm{N}_{\mathrm{i}}=15\right), \operatorname{LWGR} /$ PTGR $\left(\mathrm{N}_{\mathrm{i}}=15\right)$, and FBR $\left(\mathrm{N}_{\mathrm{i}}=2\right)$ [1]. Some studies $[16,18,20,27]$ performed the LCA by combining the BWR and the PWR nuclear power generation systems, and referred to them as the light water reactors (LWRs) based on the categorization in accordance with the medium of moderator. Accordingly, this study adopted the use of LWR as an additional category to the general classification (BWR, PWR, HWR, GCR, LWGR/PTGR, and FBR) proposed by the Nuclear Engineering International Handbook [33] in quantifying the lifecycle GHG emissions from nuclear power generation systems. Each of the reviewed nuclear LCA study case descriptions was first categorized on the basis of the reactor type. Next, the lifecycle GHG emissions from the reactor-based and the fuel enrichment method-based nuclear power generation systems were quantified using statistical metrics (sample size, mean, standard deviation, minimum, maximum, standard error of the mean, quartile 1, quartile 2 or median, quartile 3 ) and graphical representations (error bars representing the mean with $95 \%$ confidence intervals, box plots representing the quartiles with outliers). The sample size is a measure that indicates the total number of observations. The mean is a measure that represents the central tendency of the observed data. The standard deviation is a measure used to quantify the degree of variation within a set of observations from a single sample. The minimum and maximum measures define the least observation and the highest observation with a considered sample, respectively. The standard error of the mean is a measure that estimates the variability between sample means obtained by taking multiple samples from the same population. The standard error of the mean determines the precision between the mean of the sample estimates and the population mean. The quartile statistics are a set of three measures that divide a ranked set of observed data values into four equal groups with each group comprising a quarter of the data. While the error bars demonstrate the degree of confidence in the mean GHG emissions, the box plots provide information on the degree of variation among the LCA studies characterized by different biomass feedstock categories.

This study is limited in its scope by not including the category of small modular reactors (SMRs) that are capable of generating the power on a small scale and have been gaining prominence in recent years. 


\section{Results and Discussion}

\subsection{Review of Nuclear LCA Studies}

There are numerous studies [4-29] that evaluated the lifecycle environmental impacts of using nuclear reactors for power generation. One needs to define the system boundary conditions (that includes details on the activities or processes to be considered in the analysis) and a functional unit of measure (that enables quantification of the net environmental impacts from carrying out an activity or a process as defined within the LCA system boundary conditions) when performing a LCA.

The majority of the aforementioned studies $[4-12,14-27,29]$ that performed the LCA of nuclear power generation systems defined the system boundary conditions to include front-end activities (mining, milling, refinery, conversion, enrichment, fuel fabrication), operation of power plants to generate electricity, back-end activities (interim storage, waste conditioning, waste disposal), transportation, construction of the nuclear power plant, and decommissioning of the nuclear power plant. One study [13] defined their boundary conditions to include all the activities associated with the majority of the studies that are listed above and the only exception being that the fuel cycle results were borrowed from the then existing literature. The remaining study [28] considered all the activities associated with the majority of the studies that are listed above and additionally included the activities related to power distribution to end users.

The common functional unit of measure adopted by the majority of the nuclear LCA studies is grams of $\mathrm{CO}_{2}$ equivalent per kilowatt hour $\left(\mathrm{gCO}_{2} \mathrm{e} / \mathrm{kWh}\right)$ of electricity produced. Accordingly, this study also adopted the functional unit of measure for GHG emissions to be $\mathrm{gCO}_{2} \mathrm{e} / \mathrm{kWh}$ of electricity produced.

Table 1 provides a summary of the GHG emissions (in $\mathrm{gCO}_{2} \mathrm{e} / \mathrm{kWh}$ ) for $\Delta$ different nuclear reactor types on the basis of the reviewed 26 nuclear power generation LCA studies (having 49 case representations). Table 1 also provides additional details such as the electricity generation capacity (EGC, in MW), the thermal efficiency $\left(\eta_{t}\right.$, in \%), the capacity factor $(C F$, in \%), the plant lifetime (PL, in years), the fuel enrichment method (FEM-gaseous diffusion (D), centrifuge (C), mixture with gaseous diffusion dominance $(M-D)$, mixture with centrifuge dominance $(M-C)$, mixture with equivalent proportions of gaseous diffusion and centrifuge (M-DC)), the uranium ore-grade (UOG, in \%), the LCA method type (LCA Type-process analysis (Process), input-output analysis (I-O), mix of process analysis with input-output analysis (Hybrid)), and the geographical location (GL) for the installed nuclear power generation systems. The EGC may be defined as the amount of electrical power that is produced under standard operating conditions. $\eta_{t}$ is the ratio of gross electricity generated to thermal energy. It is related to the difference in temperature between the steam from the reactor and the coolant. The CF is the ratio of the average power generated to the rated peak power. The PL indicates the licensed operational life span of the nuclear reactor considered in the study. The FEM indicates the type of process adapted in fuel (uranium) enrichment. The UOG denotes the grade of uranium. The GL indicates the site-specific location of the nuclear power plant being examined.

Based on the review of 26 nuclear power generation LCA studies (with 49 case representations, refer to Table 1), one may note that the PWR $(\mathrm{N}=21)$ nuclear power generation systems were more in number compared to the BWR $(\mathrm{N}=15), \operatorname{LWR}(\mathrm{N}=7), \operatorname{HWR}(\mathrm{N}=3), \operatorname{FBR}(\mathrm{N}=2)$, and GCR $(\mathrm{N}=1)$. There were no LCA studies on the use of LWGR nuclear power generation systems. 
Table 1. GHG emissions for reactor-based nuclear power generation systems.

\begin{tabular}{|c|c|c|c|c|c|c|c|c|c|c|}
\hline Source & $\begin{array}{c}\text { Nuclear Reactor } \\
\text { Type }\end{array}$ & $\begin{array}{l}\text { GHG Emissions } \\
\left(\mathrm{gCO}_{2} \mathrm{e} / \mathrm{kWh}\right)\end{array}$ & EGC (MW) & $\eta_{t}(\%)$ & CF (\%) & PL (years) & FEM Type & UOG (\%) & LCA Type & GL \\
\hline Meridian Corporation [4] & BWR & 8.59 & 1000 & & 70 & 30 & $\mathrm{D}$ & 0.17 & Process & USA \\
\hline San Martin [5] & BWR & 8 & 1000 & & 70 & 30 & $\mathrm{D}$ & 0.17 & Process & USA \\
\hline Yasukawa et al. [6] & PWR & 34 & 1000 & 33 & 75 & 30 & $\mathrm{D}$ & & Hybrid & Japan \\
\hline \multirow{2}{*}{ Yasukawa et al. [7] } & PWR & 25.7 & 1100 & & & & $\mathrm{D}$ & & Hybrid & Japan \\
\hline & PWR & 7.9 & 1100 & & & & $\mathrm{C}$ & & Hybrid & Japan \\
\hline \multirow{3}{*}{ Uchiyama [8] } & FBR & 7.8 & 1000 & 33 & 75 & 30 & $\mathrm{C}$ & & Hybrid & Japan \\
\hline & BWR & 10.4 & 1000 & 32 & 75 & 30 & $\mathrm{C}$ & & Hybrid & Japan \\
\hline & BWR & 21.1 & 1000 & 32 & 75 & 30 & $\mathrm{D}$ & & Hybrid & Japan \\
\hline \multirow{2}{*}{ Dones et al. [9] } & PWR & 6 & 600 & & 87 & 60 & $\mathrm{C}$ & & Process & Switzerland \\
\hline & BWR & 6 & 1300 & & 87 & 60 & $\mathrm{C}$ & & Process & Switzerland \\
\hline \multirow[t]{2}{*}{ Andseta et al. [10] } & $\begin{array}{c}\text { HWR } \\
\text { (best case) }\end{array}$ & 3.2 & $600-900$ & 31 & 80 & 40 & & & Process & Canada \\
\hline & $\begin{array}{c}\text { HWR } \\
\text { (worst case) }\end{array}$ & 15.41 & $600-900$ & 31 & 80 & 40 & & & Process & Canada \\
\hline \multirow{6}{*}{ Hondo et al. [11] } & $\begin{array}{c}\text { BWR } \\
\text { (Pu recycle) }\end{array}$ & 11 & 1000 & 32 & 70 & 30 & $\mathrm{C}$ & & Hybrid & Japan \\
\hline & $\begin{array}{c}\text { BWR } \\
\text { (Pu recycle) }\end{array}$ & 21.6 & 1000 & 32 & 70 & 30 & M-DC & & Hybrid & Japan \\
\hline & $\begin{array}{c}\text { PWR } \\
\text { (Pu recycle) }\end{array}$ & 24.7 & 1000 & 32 & 70 & 30 & M-DC & & Hybrid & Japan \\
\hline & $\begin{array}{c}\text { BWR } \\
\text { (no Pu recycle) }\end{array}$ & 26.4 & 1000 & 32 & 70 & 30 & M-DC & & Hybrid & Japan \\
\hline & $\begin{array}{c}\text { PWR } \\
\text { (no Pu recycle) }\end{array}$ & 31.4 & 1000 & 32 & 70 & 30 & M-DC & & Hybrid & Japan \\
\hline & $\begin{array}{c}\text { BWR } \\
\text { (Pu recycle) }\end{array}$ & 37 & 1000 & 32 & 70 & 30 & $\mathrm{D}$ & & Hybrid & Japan \\
\hline Rashad and Hammad [12] & PWR & 25.7 & 1000 & & 75 & 30 & $\mathrm{D}$ & 0.2 & Process & \\
\hline \multirow{2}{*}{ Voorspools et al. [13] } & PWR & 1.8 & 1000 & 33 & 85 & 40 & M-DC & 0.2 & Process & Belgium \\
\hline & PWR & 4 & 1000 & 33 & 85 & 40 & M-DC & 0.2 & $\mathrm{I}-\mathrm{O}$ & Belgium \\
\hline White and Kulcinski [14] & PWR & 15 & 1000 & 33 & 75 & 40 & $\mathrm{C}$ & & Hybrid & USA \\
\hline Hondo [15] & BWR & 24.2 & 1000 & 32.2 & 70 & 30 & $\mathrm{D}$ & & Hybrid & Japan \\
\hline \multirow{2}{*}{ Tokimatsu et al. [16] } & LWR & 10 & 1000 & & 90 & 60 & $\mathrm{C}$ & & Process & Japan \\
\hline & LWR & 13 & 1000 & & 90 & 60 & M-D & & Process & Japan \\
\hline
\end{tabular}


Table 1. Cont.

\begin{tabular}{|c|c|c|c|c|c|c|c|c|c|c|}
\hline Source & $\begin{array}{c}\text { Nuclear Reactor } \\
\text { Type }\end{array}$ & $\begin{array}{l}\text { GHG Emissions } \\
\left(\mathrm{gCO}_{2} \mathrm{e} / \mathrm{kWh}\right)\end{array}$ & EGC (MW) & $\eta_{t}(\%)$ & CF (\%) & PL (years) & FEM Type & UOG $(\%)$ & LCA Type & GL \\
\hline \multirow{8}{*}{ Dones et al. [17] } & PWR & 5.19 & 1000 & 32 & 88.7 & 40 & M-D & & Process & Switzerland \\
\hline & PWR & 5.18 & 1000 & 32 & 88.7 & 40 & $\mathrm{M}-\mathrm{C}$ & & Process & Switzerland \\
\hline & PWR & 9.8 & 1000 & 33 & 84.6 & 40 & $\mathrm{M}-\mathrm{C}$ & & Process & Germany \\
\hline & PWR & 5.95 & 1000 & 33 & 71.7 & 40 & $\mathrm{D}$ & & Process & France \\
\hline & PWR & 7.74 & 1000 & 33 & 80.4 & 40 & M-D & & Process & Europe \\
\hline & BWR & 11 & 1000 & 32 & 88.7 & 40 & M-D & & Process & Switzerland \\
\hline & BWR & 10.7 & 1000 & 32 & 88.7 & 40 & $\mathrm{M}-\mathrm{C}$ & & Process & Germany \\
\hline & BWR & 7.45 & 1000 & 32 & 88.7 & 40 & M-D & & Process & Europe \\
\hline EPD Report [18] & $\begin{array}{c}\text { LWR } \\
\text { (1 BWR, } 3 \text { PWRs) }\end{array}$ & 3.8 & 3671 & 34 & 90 & 50 & $\mathrm{C}$ & & Process & $\begin{array}{c}\text { Värö } \\
\text { Peninsula, } \\
\text { Sweden }\end{array}$ \\
\hline EPD Report [19] & BWR & 3.3 & 3274 & 34 & 90 & 50 & $\mathrm{C}$ & & Process & $\begin{array}{l}\text { Forsmark, } \\
\text { Sweden }\end{array}$ \\
\hline \multirow{3}{*}{ Fthenakis and Kim [20] } & $\begin{array}{c}\text { LWR } \\
\text { (best case) }\end{array}$ & 16 & 1100 & & 85 & 40 & $\mathrm{D}$ & 12.7 & Hybrid & USA \\
\hline & $\begin{array}{c}\text { LWR } \\
\text { (baseline case) } \\
\end{array}$ & 25 & 1100 & & 85 & 40 & $\mathrm{D}$ & 0.2 & Hybrid & USA \\
\hline & $\begin{array}{c}\text { LWR } \\
\text { (worst case) }\end{array}$ & 55 & 1100 & & 85 & 40 & $\mathrm{D}$ & & Process & USA \\
\hline \multirow{3}{*}{ NEEDS Report [21] } & PWR & 5.91 & 1000 & 34 & & 40 & $\mathrm{D}$ & & Process & Europe \\
\hline & PWR & 5.58 & 1590 & 37 & & 60 & $\mathrm{C}$ & & Process & Europe \\
\hline & FBR & 4.72 & 1450 & 40 & & 40 & & & Process & Europe \\
\hline EPD Report [22] & GCR & 8.35 & 1185 & & & 35 & $\mathrm{C}$ & & Process & Scotland \\
\hline EPD Report [23] & PWR & 3.54 & $730(2 \times 365)$ & & & 50 & $\mathrm{C}$ & & Process & $\begin{array}{c}\text { Canton of } \\
\text { Aargau, } \\
\text { Switzerland }\end{array}$ \\
\hline Kunakemakorn et al. [24] & PWR & 1.98 & 1630 & 37 & 94 & 60 & $\mathrm{D}$ & & Process & Canada \\
\hline Santoyo-Castelazo et al. [25] & BWR & 11 & 1365 & 32.8 & 91 & 100 & & & Process & Mexico \\
\hline Kumari and Rao [26] & HWR & 66 & 4560 & & & 100 & & & Process & India \\
\hline Nian et al. [27] & LWR & 20.68 & 1000 & 33 & 70 & 60 & & & Process & Japan \\
\hline Pereira et al. [28] & PWR & 16.95 & 1250 & & 70 & 40 & & & Process & Japan \\
\hline Poinssot et al. [29] & PWR & 5.29 & 63400 & & & $20-50$ & C & & Process & France \\
\hline
\end{tabular}


The GHG emissions were found to be lower for the case representations that had recycled plutonium (refer to the GHG emissions data provided by Hondo et al. [11] for LWR (BWR, PWR) nuclear power generation systems in Table 1). It may also be noted that the GHG emissions decreased with an increase in the uranium ore grade (refer to the GHG emissions data provided by Fthenakis and Kim [20] for LWR nuclear power generation systems in Table 1). This phenomenon of higher GHG emissions being associated with lower uranium ore grades may be attributed to the requirement of high energy intensities for lower uranium ore grades. Similar observations were made by another study [34] that noted GHG emissions were lower for nuclear power generation systems utilizing higher uranium ore grades $(0.1 \%-2 \%)$ in comparison with the nuclear power generation systems operating with lower uranium ore grades $(0.01 \%-0.02 \%)$. In the United States of America (USA), the Nuclear Regulatory Commission (NRC) provides an initial operating license for a period of 40 years for newly built nuclear power plants. Towards the end of the nuclear plant lifetime, the owners (i.e., the licensees) may choose to go for a 20 year extension under the NRC's established timely license renewal process (codified in 10 CFR Part 51 and 10 CFR Part 54). The NRC has granted operating license renewals to 74 of the 100 operating reactors in the USA for a period of additional 20 years [35].

\subsection{Statistical Evaluation of Nuclear LCA Studies}

Figure 1 provides a graphical representation of the (a) error bars (mean $\pm 95 \%$ confidence interval (CI) statistics) and (b) box plots (quartiles + outlier statistics) for GHG emissions from the different reactor-based nuclear power generation systems reviewed in this study. Table 2 provides a statistical summary of the lifecycle GHG emissions with details on the sample size $(\mathrm{N})$, mean $(\mathrm{X}) \pm$ standard deviation (SD), minimum (Min.), maximum (Max.), standard error of the mean (SE), quartile 1 (Q1), quartile 2 or median (Q2), and quartile 3 (Q3) for the different reactor-based nuclear power generation systems reviewed in this study.

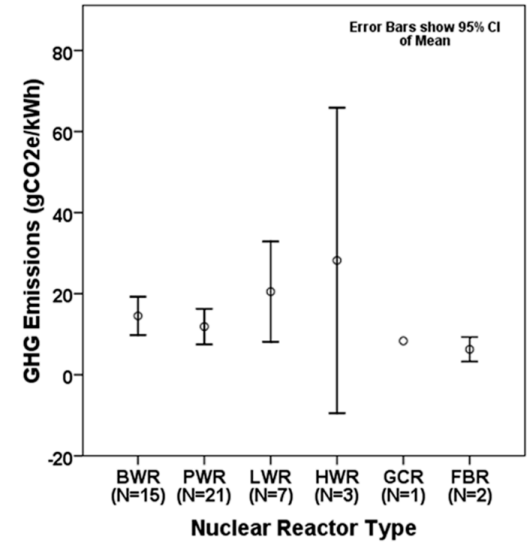

(a)

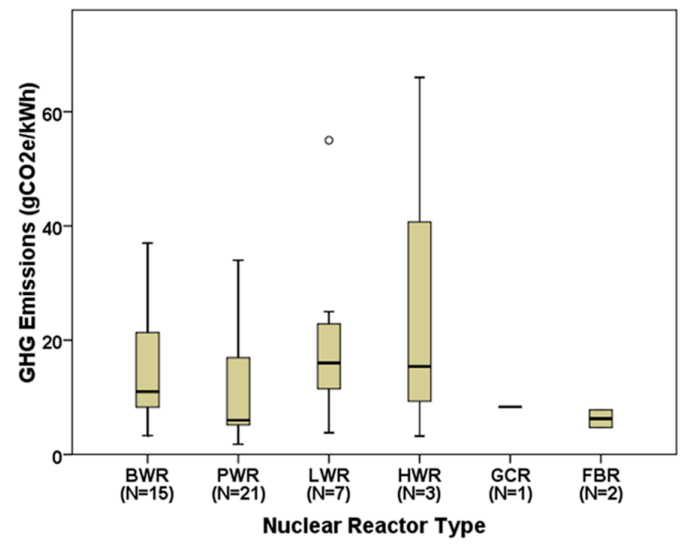

(b)

Figure 1. GHG emissions from different nuclear power generation systems: (a) mean $\pm 95 \% \mathrm{CI}$ error bars; and (b) quartile box plots.

Table 2. GHG emission $\left(\mathrm{gCO}_{2} \mathrm{e} / \mathrm{kWh}\right)$ statistics from different nuclear power generation systems.

\begin{tabular}{ccccccccc}
\hline Nuclear Reactor Type & $\mathbf{N}$ & $\mathbf{X} \pm \mathbf{S D}$ & Min. & Max. & SE & Q1 & Q2 & Q3 \\
\hline BWR & 15 & $14.52 \pm 9.37$ & 3.3 & 37 & 2.42 & 8 & 11 & 21.6 \\
PWR & 21 & $11.87 \pm 10.24$ & 1.8 & 34 & 2.24 & 5.18 & 6 & 15 \\
LWR & 7 & $20.5 \pm 16.71$ & 3.8 & 55 & 6.32 & 10 & 16 & 25 \\
HWR & 3 & $28.2 \pm 33.3$ & 3.2 & 66 & 19.22 & 3.2 & 15.41 & 66 \\
GCR & 1 & $8.35 \pm 0$ & 8.35 & 8.35 & 0 & 8.35 & 8.35 & 8.35 \\
FBR & 2 & $6.26 \pm 2.18$ & 4.72 & 7.8 & 1.54 & 4.72 & 6.26 & 7.8 \\
\hline
\end{tabular}


From Figure 1a and Table 2, one may note that the mean lifecycle GHG emissions obtained from the use of BWR, PWR, LWR, HWR, GCR, and FBR in nuclear power generation systems are $14.52 \mathrm{gCO}_{2} \mathrm{e} / \mathrm{kWh}, 11.87 \mathrm{gCO}_{2} \mathrm{e} / \mathrm{kWh}, 20.5 \mathrm{gCO}_{2} \mathrm{e} / \mathrm{kWh}, 28.2 \mathrm{gCO}_{2} \mathrm{e} / \mathrm{kWh}, 8.35 \mathrm{gCO}_{2} \mathrm{e} / \mathrm{kWh}$, and $6.26 \mathrm{gCO}_{2} \mathrm{e} / \mathrm{kWh}$, respectively. These results indicate that lower GHGs are emitted from the FBR nuclear power generation systems in comparison to the widely adopted LWR (PWR/BWR) and HWR nuclear power generation systems. This is because the FBR nuclear power generation systems involves the recycling of plutonium (which is the bulk of long life radioactive waste) in its entirety, while the LWR nuclear power generation systems permit only partial recycling of plutonium with MOX fuel loading [22]. The relatively higher mean lifecycle GHG emissions from HWR nuclear power generation systems may be attributed to the process of heavy water production being highly energy intensive $[10,32,36]$. The highest mean lifecycle GHG emission in this study was obtained from the HWRs (refer to Table 2). The highest mean lifecycle GHG emission from the HWR reactors $\left(28.2 \mathrm{gCO}_{2} \mathrm{e} / \mathrm{kWh}\right)$ in this study was $108 \%, 108 \%, 62.7 \%, 33.2 \%, 5.7 \%, 3.9 \%$, and $3.2 \%$ of the mean lifecycle GHG emissions from hydroelectricity $\left(26 \mathrm{gCO}_{2} \mathrm{e} / \mathrm{kWh}\right)$, wind $\left(26 \mathrm{gCO}_{2} \mathrm{e} / \mathrm{kWh}\right)$, biomass $\left(45 \mathrm{gCO}_{2} \mathrm{e} / \mathrm{kWh}\right)$, solar photovoltaics $\left(85 \mathrm{gCO}_{2} \mathrm{e} / \mathrm{kWh}\right)$, natural gas $\left(499 \mathrm{gCO}_{2} \mathrm{e} / \mathrm{kWh}\right)$, oil $\left(733 \mathrm{gCO}_{2} \mathrm{e} / \mathrm{kWh}\right)$, and coal $\left(888 \mathrm{gCO}_{2} \mathrm{e} / \mathrm{kWh}\right)$ power generation systems, respectively [37]. From Figure $1 \mathrm{~b}$, one may note that the degree of variation in GHG emissions was less for FBR nuclear power generation systems, followed by PWR, BWR, LWR, and HWR nuclear power generation systems. Consequently, one may infer that the use of FBR nuclear power generation systems provides the most environmentally-friendly option amongst the six different types of nuclear power generation systems considered in this study. Note that this study has a limited sample size of two for FBR nuclear power generation systems, which is equivalent to the total number of real-world FBR nuclear power generation systems as suggested by the World Nuclear Association [1]. More LCA studies utilizing GCR nuclear power generation systems are to be considered before one generalizes the influence of GCR on the lifecycle GHG emissions (note that the mean lifecycle GHG emission statistics of GCR nuclear power generation systems in this study were based on a sample size equal to one).

Figure 2 provides a graphical representation of the (a) error bars (mean $\pm 95 \%$ CI statistics) and (b) box plots (quartiles + outlier statistics) for GHG emissions with respect to different fuel enrichment methods. Table 3 provides a statistical summary of the lifecycle GHG emissions for different fuel enrichment methods associated with the reviewed 26 nuclear LCA studies. From Figure 2a and Table 3, one may note that the mean lifecycle GHGs associated with the use of C, D, M-C, M-D, and M-DC fuel enrichment methods in nuclear power generation systems are $7.43 \mathrm{gCO}_{2} \mathrm{e} / \mathrm{kWh}, 21 \mathrm{gCO}_{2} \mathrm{e} / \mathrm{kWh}$, $8.56 \mathrm{gCO}_{2} \mathrm{e} / \mathrm{kWh}, 8.87 \mathrm{gCO}_{2} \mathrm{e} / \mathrm{kWh}$, and $18.32 \mathrm{gCO}_{2} \mathrm{e} / \mathrm{kWh}$, respectively. These results clearly indicate that the centrifuge fuel enrichment method is a better option than the gaseous diffusion enrichment method, considering that the $100 \%$ gaseous diffusion GHG emissions exceeded the $100 \%$ centrifuge GHG emissions and the gaseous diffusion dominant mixture GHG emissions were higher than the centrifuge dominant mixture GHG emissions. The higher GHG emissions associated with gaseous diffusion enrichment method may be attributed to the higher consumption of electric load in comparison with the electricity consumption associated with centrifuge enrichment method [37]. From Figure $2 b$, one may also note that the degree of variation in GHG emissions was less for centrifuge enrichment methods in comparison with the corresponding gaseous diffusion enrichment methods. Resultantly, one may infer that the use of centrifuge enrichment method in nuclear power generation systems provides a better environmental-friendly option towards reducing GHG emissions than the gaseous diffusion enrichment method. 


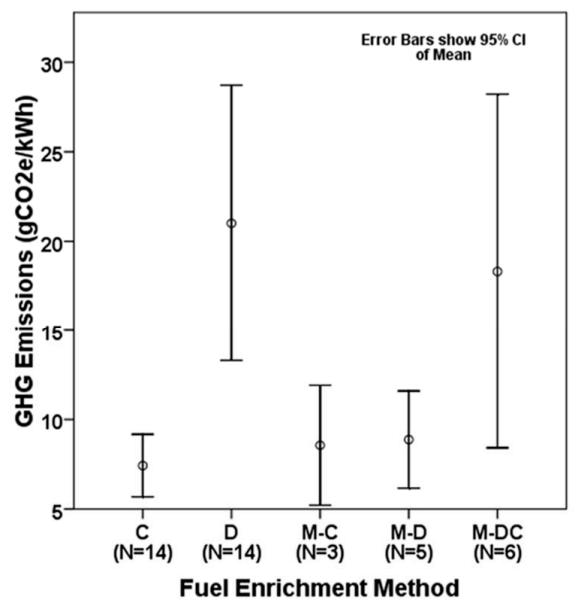

(a)

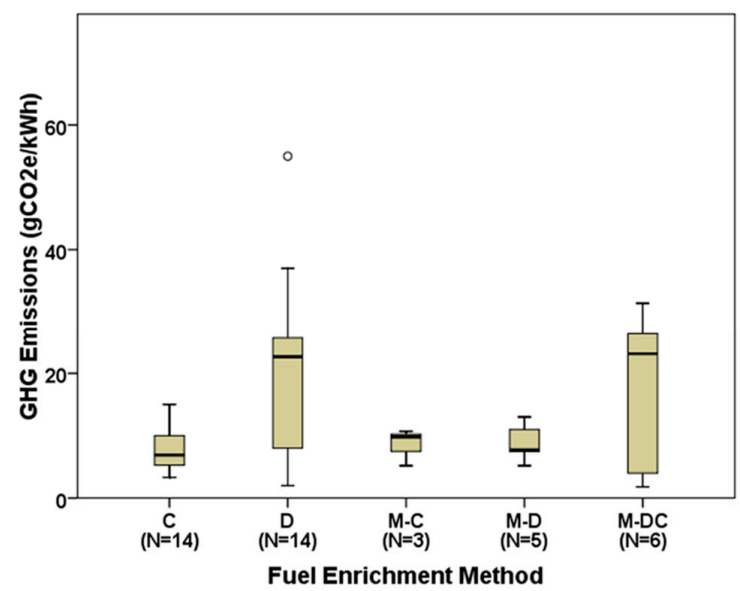

(b)

Figure 2. GHG emissions from different fuel enrichment methods: (a) mean $\pm 95 \%$ CI error bars; and (b) quartile box plots.

Table 3. GHG emission $\left(\mathrm{gCO}_{2} \mathrm{e} / \mathrm{kWh}\right)$ statistics from different fuel enrichment methods.

\begin{tabular}{ccccccccc}
\hline Fuel Enrichment Method & $\mathbf{N}$ & $\mathbf{X} \pm \mathbf{S D}$ & $\mathbf{M i n}$ & $\mathbf{M a x}$ & $\mathbf{S E}$ & $\mathbf{Q 1}$ & $\mathbf{Q 2}$ & $\mathbf{Q 3}$ \\
\hline C & 14 & $7.43 \pm 3.33$ & 3.3 & 15 & 0.89 & 5.29 & 6.9 & 10 \\
D & 14 & $21 \pm 14.72$ & 1.98 & 55 & 3.93 & 8 & 22.65 & 25.7 \\
M-C & 3 & $8.56 \pm 2.96$ & 5.18 & 10.7 & 1.71 & 5.18 & 9.8 & 10.7 \\
M-D & 5 & $8.87 \pm 3.1$ & 5.19 & 13 & 1.39 & 7.45 & 7.74 & 11 \\
M-DC & 6 & $18.32 \pm 12.38$ & 1.8 & 31.4 & 5.05 & 4 & 23.15 & 26.4 \\
\hline
\end{tabular}

\section{Conclusions}

This paper quantified the lifecycle GHG emissions from six different reactor-based nuclear power generation systems (BWR, PWR, LWR, HWR, GCR, and FBR) by performing a review of 26 nuclear LCA studies (having 49 case representations) and the subsequent computation of statistical metrics with development of associated graphical representations. Additionally, this study also quantified the lifecycle GHG emissions with respect to the type of fuel enrichment method.

Lower lifecycle GHG emissions were noted for those nuclear power generation systems that recycled plutonium in comparison to those nuclear power generation systems that did not recycle plutonium. The lifecycle GHG emissions from nuclear power generation systems utilizing low quality uranium ore grades (requiring high energy intensity) were higher than those nuclear power generation systems operating with high quality uranium ore grades.

The mean lifecycle GHG emissions obtained from the use of BWR, PWR, LWR, HWR, GCR, and FBR in nuclear power generation systems are $14.52 \mathrm{gCO}_{2} \mathrm{e} / \mathrm{kWh}, 11.87 \mathrm{gCO}_{2} \mathrm{e} / \mathrm{kWh}$, $20.5 \mathrm{gCO}_{2} \mathrm{e} / \mathrm{kWh}, 28.2 \mathrm{gCO}_{2} \mathrm{e} / \mathrm{kWh}, 8.35 \mathrm{gCO}_{2} \mathrm{e} / \mathrm{kWh}$, and $6.26 \mathrm{gCO}_{2} \mathrm{e} / \mathrm{kWh}$, respectively. The FBR nuclear power generation systems proved to be the most environmentally-friendly option (with minimal GHG emissions and minimal quartile variation) amongst the six different types of nuclear power generation systems considered in this study. This study captured the variation in the performance of FBR nuclear power generation systems in its entirety, considering that the sample size for FBR nuclear power generation system LCA studies reviewed in this study and the total number of FBR nuclear power generation systems operating in the real-world are both equivalent to two. The highly energy intensive heavy water production process contributed considerably towards higher lifecycle GHG emissions from HWR nuclear power generation systems.

The mean lifecycle GHGs associated with the use of C, D, M-C, M-D, and M-DC fuel enrichment methods from nuclear power generation systems reviewed in this study are $7.43 \mathrm{gCO}_{2} \mathrm{e} / \mathrm{kWh}$, 
$21 \mathrm{gCO}_{2} \mathrm{e} / \mathrm{kWh}, 8.56 \mathrm{gCO}_{2} \mathrm{e} / \mathrm{kWh}, 8.87 \mathrm{gCO}_{2} \mathrm{e} / \mathrm{kWh}$, and $18.32 \mathrm{gCO}_{2} \mathrm{e} / \mathrm{kWh}$, respectively. The nuclear power generation systems that adopted the use of centrifuge enrichment method yielded lower lifecycle GHG emissions in comparison to the nuclear power generation systems that implemented the gaseous diffusion enrichment method that required higher electric loads. More research efforts are needed to study the LCA of GCR nuclear power generation systems, considering that there was only a single LCA case representation for the GCR nuclear power generation systems. Future nuclear LCA studies must focus on addressing the lifecycle GHG emissions from SMRs that has not been covered in this study.

Acknowledgments: This work was supported by the US National Science Foundation through the CREST Center for Energy and Environmental Sustainability (CEES) at Prairie View A \& M University, award number 1036593.

Author Contributions: Raghava Kommalapati developed the research idea and created the team; Akhil Kadiyala conceived the approach to scrutinized nuclear power lifecycle GHG emissions in detail and developed the manuscript under the guidance of Raghava Kommalapati and Ziaul Huque.

Conflicts of Interest: The authors declare no conflict of interest.

\section{References}

1. World Nuclear Association. Nuclear Power Reactors. Available online: http://www.world-nuclear.org/ info/Nuclear-Fuel-Cycle/Power-Reactors/Nuclear-Power-Reactors/ (accessed on 26 January 2016).

2. International Energy Statistics. Available online: http://www.eia.gov/cfapps/ipdbproject/iedindex3.cfm? tid=44\&pid=44\&aid=2\&cid=ww,r1,\&syid=2008\&eyid=2012\&unit=QBTU (accessed on 9 November 2015).

3. United States Energy Information Administration. International Energy Outlook 2013. Available online: http://www.eia.gov/forecasts/ieo/pdf/0484(2013).pdf (accessed on 9 November 2015).

4. Energy Technology Data Exchange World Energy Base (ETDEWEB). Meridian Corporation. Energy System Emissions and Materiel Requirements. Available online: https:/ /www.etde.org/etdeweb/servlets/purl/ 860706-4YG3j9/860706.pdf (accessed on 14 June 2016).

5. San Martin, R.L. Environmental Emissions from Energy Technology Systems: The Total Fuel Cycle. Available online: http://www.fischer-tropsch.org/DOE/DOE_reports/OSTI/OSTI_860643/OSTI\%20860643.pdf (accessed on 14 June 2016).

6. Yasukawa, S.; Tadokoro, Y.; Kajiyama, T. Lifecycle $\mathrm{CO}_{2}$ emission from nuclear power reactor and fuel cycle system. In Proceedings of the Expert Workshop on Life-Cycle Analysis of Energy Systems, Methods and Experience, Paris, France, 21-22 May 1992; pp. 151-160.

7. Yasukawa, S.; Tadokoro, Y.; Sato, O.; Yamaguchi, M. Integration of Indirect $\mathrm{CO}_{2}$ Emissions from the Full Energy Chain. Available online: http://www.iaea.org/inis/collection/NCLCollectionStore/_Public/28/ 013/28013033.pdf (accessed on 14 June 2016).

8. Uchiyama, Y. Lifecycle analysis of electricity generation and supply systems. In Electricity, Health and the Environment: Comparative Assessment in Support of Decision Making; International Atomic Energy Agency: Vienna, Austria, 1995; pp. 279-291.

9. Dones, R.; Gantner, U.; Hirschberg, S.; Doka, G.; Knoepfel, I. Environmental Inventories for Future Electricity Supply Systems for Switzerland. Available online: http://www.iaea.org/inis/collection/ NCLCollectionStore/_Public/27/025/27025674.pdf?r=1 (accessed on 14 June 2016).

10. Andseta, S.; Thompson, M.J.; Jarrell, J.P.; Pendergast, D.R. CANDU reactors and greenhouse gas emissions. In Proceedings of the 11th Pacific Basin Nuclear Conference, Banff, AB, Canada, 3-7 May 1998.

11. Hondo, H.; Uchiyama, Y.; Moriizumi, Y. Evaluation of Power Generation Technologies Based on Lifecycle $\mathrm{CO}_{2}$ Emissions-Reestimation Using the Latest Data and Effects of the Difference of Conditions; Report No. 99009; Central Research Institute of Electric Power Industry: Tokyo, Japan, 2000.

12. Rashad, S.M.; Hammad, F.H. Nuclear power and the environment: Comparative assessment of environmental and health impacts of electricity generating systems. Appl. Energy 2000, 65, 211-229. [CrossRef]

13. Voorspools, K.R.; Brouwers, E.A.; D'haeseleer, W.D. Energy content and indirect greenhouse gas emissions embedded in 'emission-free' plants: results from the low countries. Appl. Energy 2000, 67, 307-330. [CrossRef] 
14. White, S.W.; Kulcinski, G.L. Birth to death analysis of the energy payback ratio and $\mathrm{CO}_{2}$ gas emission rates from coal, fission, wind, and DT-fusion electrical power plants. Fusion Eng. Des. 2000, 48, 473-481. [CrossRef]

15. Hondo, H. Lifecycle GHG emission analysis of power generation systems: Japanese case. Energy 2005, 30, 2042-2056. [CrossRef]

16. Tokimatsu, K.; Kosugi, T.; Asami, T.; Williams, E.; Kaya, Y. Evaluation of lifecycle $\mathrm{CO}_{2}$ emissions from the Japanese electric power sector in the 21st century under various nuclear scenarios. Energy Policy 2006, 34, 833-852. [CrossRef]

17. Dones, R.; Bauer, C.; Bolliger, R.; Burger, B.; Heck, T.; Roder, A.; Emmenegger, M.F.; Frischknecht, R.; Jungbluth, N.; Tuchschmid, M. Lifecycle Inventories of Energy Systems: Results for Current Systems in Switzerland and Other UCTE Countries. Available online: http:/ / ecolo.org/documents/documents_in_ english/Life-cycle-analysis-PSI-05.pdf (accessed on 14 June 2016).

18. Environmental Product Declaration. Certified Environmental Product Declaration EPD of Electricity from Ringhals Nuclear Power Plant. Available online: http://gryphon.environdec.com/data/files/6/9916/ epd26_Vattenfall_Ringhals_Nuclear_Power_Plant_2014-03-27.pdf (accessed on 14 June 2016).

19. Environmental Product Declaration. Certified Environmental Product Declaration EPD of Electricity from Forsmark Nuclear Power Plant. Available online: http://gryphon.environdec.com/data/files/6/9914/ epd21_Vattenfall_Forsmark_Nuclear_Power_Plant_2014-03-27.pdf (accessed on 14 June 2016).

20. Fthenakis, V.M.; Kim, H.C. Greenhouse-gas emissions from solar electric- and nuclear power: A life-cycle study. Energy Policy 2007, 35, 2549-2557. [CrossRef]

21. New Energy Externalities Developments for Sustainability (NEEDS) Report. Final Report on Technical Data, Costs, and Lifecycle Inventories of Nuclear Power Plants. Available online: http:/ / www.needs-project.org/ RS1a/RS1a\%20D14.2\%20Final\%20report\%20on\%20nuclear.pdf (accessed on 14 June 2016).

22. Environmental Product Declaration. Environmental Product Declaration of Electricity from Torness Nuclear Power Station. Available online: https://www.edfenergy.com/sites/default/files/torness_epd_report_final. pdf (accessed on 14 June 2016).

23. Environmental Product Declaration. Beznau Nuclear Power Plant. Available online: http://www.axpo.com/ content/dam/axpo/switzerland/umwelt/dokumente/umweltdeklaration_beznau_en.pdf (accessed on 14 June 2016).

24. Kunakemakorn, J.; Wongsuchoto, P.; Pavasant, P.; Laosiripojana, N. Greenhouse gas emission of European pressurized reactor (EPR) nuclear power plant technology: A lifecycle approach. J. Sustain. Energy Environ. 2011, 2, 45-50.

25. Santoyo-Castelazo, E.; Gujba, H.; Azapagic, A. Lifecycle assessment of electricity generation in Mexico. Energy 2011, 36, 1488-1499. [CrossRef]

26. Kumari, S.; Rao, P.S. Electricity from nuclear power: Is it a solution to greenhouse gas emissions in India. Int. J. Sci. Technol. Res. 2013, 2, 242-247.

27. Nian, V.; Chou, S.K.; Su, B.; Bauly, J. Lifecycle analysis on carbon emissions from power generation-The nuclear energy example. Appl. Energy 2014, 118, 68-82. [CrossRef]

28. Pereira, J.P.; Parady, G.T.; Dominguez, B.C. Japan's energy conundrum: Post-Fukushima scenarios from a lifecycle perspective. Energy Policy 2014, 67, 104-115. [CrossRef]

29. Poinssot, Ch.; Bourg, S.; Ouvrier, N.; Combernoux, N.; Rostaing, C.; Vargas-Gonzalez, M.; Bruno, J. Assessment of the environmental footprint of nuclear energy systems: Comparison between closed and open fuel cycles. Energy 2014, 69, 199-211. [CrossRef]

30. Nuclear Energy. Advantages and Disadvantages of Nuclear Power. Available online: http://nuclear-energy. net/advantages-and-disadvantages-of-nuclear-energy.html (accessed on 9 November 2015).

31. Warner, E.S.; Heath, G.A. Lifecycle greenhouse gas emissions of nuclear electricity generation. J. Ind. Ecol. 2012, 16, S73-S92. [CrossRef]

32. Lenzen, M. Lifecycle energy and greenhouse gas emissions of nuclear energy: A review. Energy Convers. Manag. 2008, 49, 2178-2199. [CrossRef]

33. Nuclear Engineering International. World Nuclear Industry Handbook. Available online: http://viewer. zmags.com/publication/95b5bc6a\#/95b5bc6a/1 (accessed on 9 November 2015).

34. Austrian Energy Agency. Energy Balance of Nuclear Power Generation. Available online: http:/ / www.ecology.at/files/berichte/E22.595.pdf (accessed on 9 November 2015). 
35. United States Energy Information Administration. Today in Energy. Available online: http://www.eia.gov/ todayinenergy / detail.cfm?id=18591 (accessed on 14 September 2016).

36. Storm van Leeuwen, J.W.; Smith, P. Nuclear Power: The Energy Balance. Available online: http:/ / www.stormsmith.nl/reports.html (accessed on 9 November 2015).

37. World Nuclear Association. Comparison of Lifecycle Greenhouse Gas Emissions of Various Electricity Generation Sources. Available online: http:/ /www.world-nuclear.org/uploadedFiles/org/WNA/ Publications/Working_Group_Reports/comparison_of_lifecycle.pdf (accessed on 14 June 2016).

(C) 2016 by the authors; licensee MDPI, Basel, Switzerland. This article is an open access article distributed under the terms and conditions of the Creative Commons Attribution (CC-BY) license (http:/ / creativecommons.org/licenses/by/4.0/). 